\title{
The Relationship between a Mobile Device and a Shopper's Trust for E-payment Systems
}

\author{
Thair Al-Dala'in, Peter Summons and Suhuai Luo \\ School of Design, Communication \& IT \\ The University of Newcastle \\ Callaghan, AUSTRALIA \\ Thair.Al-Dalain, Peter.Summons,Suhuai.Luo@newcastle.edu.au
}

\begin{abstract}
This paper describes an attempt to identify the relationships between the using of a mobile device and an online shopper's trust in use of electronic payment systems in order to see how the adoption of a mobile device can contributes positively to increase shoppers' trust in their used of electronic payment systems. Therefore, this trust will increase shopper's intention to purchase online. It also investigated whether the availability of a security-enabled mobile device, modified to provide added security for an online shopper's payment details, would influence their intention to use online shopping. The study was based on a well-established theoretical model for the adoption of a Mobile Device Payment System (MDPS) with the Technology Acceptance Model (TAM). Structural Equation Model (SEM) techniques were used to analyze the data. Results from a survey showed that the adoption of mobile devices had strongest direct effect on increase an online shopper's trust in the electronic payment systems.
\end{abstract}

\section{Keywords- E-commerce; e-payment; security; trust}

\section{INTRODUCTION}

The nature of the online interactions used in electronic commerce (e-commerce) systems, without the cues that faceto-face contact affords, requires trust for successful communication and secure payment. A fundamental requirement must be that shoppers ought to have absolute trust in the online system in which they participate. Therefore, any adoption of e-commerce must consider trust as an important determinant of adoption behavior. At the outset it is appropriate to note several different understandings of trust which have been used in the literature, for example trust has been defined as "the willingness of a party to be vulnerable to the actions of another party based on the expectation that the other will perform a particular action important to the trustor, irrespective of the ability to monitor or control that other party" [1]. Trust is the enabling of confidence that something will or will not occur in a predictable manner. The enabling of confidence is supported by identification, authentication, authorization, and availability [2]. Trust has also been defined in the electronic payment system as an important (subjective) security feature which Pousttchi [3] stated as the degree to which a shopper believes that using a particular electronic payment (e-payment) system would be secure.

Hundreds of e-payment services as well as Internet banking were introduced all over the world by using mobile devices in their architecture in order to initiate, activate, and confirm the payment. However, little research to date has examined the use of a Mobile Device Payment System (MDPS) in online shopping [4]. Furthermore, as current e-payment mechanisms cannot offer prior knowledge of possible malicious behaviors by merchants, we need to ask how the belief in a payment system's security can be improved so as to facilitate shopper's trust in the system, and hence make them more willing to engage in future e-commerce transactions without concerns about the trust-worthiness of the merchant.

Several theories have been proposed to explain user adoption and acceptance of new technologies, including, but not restricted to, diffusion of innovations, the theory of reasoned action, and the Technology Adoption Model (TAM) [5]. Among these theories, TAM is the most used, tested, and replicated for explaining new technology usage. A critical review of TAM has revealed that there is a need to include other components in order to gain a broader view and a better explanation of information technology (IT) adoption. In line with this observation, several variations of the TAM model were proposed to increase the TAM parsimony by combining different IT acceptance models. For example, Venkatesh and Morris [6] included a subjective norm.

\section{THE PROPOSED RESEARCH MODEL AND HyPOTHESES}

Following an analysis of current literature on e-payment systems and discussions with a focus group consisting of people $(\mathrm{N}=5)$ interested in using e- payment systems, a set of constructs was developed that highlight the main factors that lead potential purchasers to trust e-payment systems. Four key factors were identified: the shoppers' perception of control over their electronic transaction (PC), their perception of the security built into a mobile phone (MSEC), their perception that no personal data is sent through the merchant (NDTM), and their perception of security evidence (PSE) regarding the parties prior to the transaction. Their effect on the adoption of a MDPS is shown in Fig. 1.

An e-payment adoption model was proposed that included the use of a mobile phone that acted as a security device to protect the privacy of a buyer's private payments details (credit card number) in an online payment transaction. A research study was initiated to investigate whether the availability of such a security-enabled mobile phone when shopping would influence the decision to use online shopping. The research 
study investigated the impact of the four factors on a customer's willingness to adopt a MDPS and their effect on a shopper's trust in the use of the MDPS for online purchases. As with most information systems, Internet technology adoption and use could be predicted by the TAM [5]. The proposed epayment adoption model (shown in Fig. 1) incorporates the trust factors for MDPS adoption, with TAM's major constructs (perceived usefulness (PU) and perceived ease of use (PEOU)) to predict users acceptance of the MDPS.

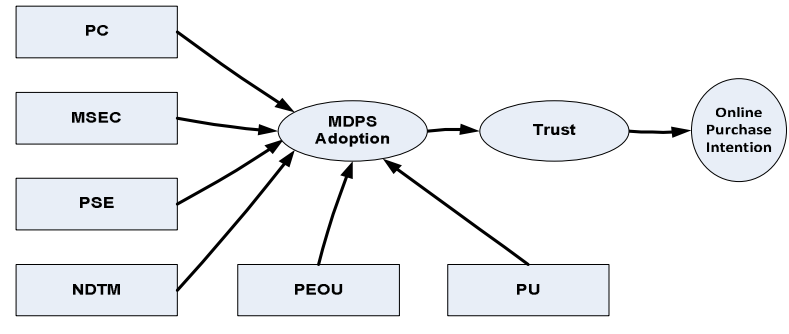

Figure 1. The proposed research model.

\section{A. perception of control}

The first factor in the adoption model is a shopper's perceived control, i.e. how much a shopper feels in control of their actions when sending their private payment information in a transaction. A review of the literature revealed perceived control to be highly significant in the context of e-commerce transactions, indicating that it has a positive effect on shoppers' attitudes and behavior [7, 8]. Control has been determined to be positively related to increased shoppers' satisfaction in an online service [9]. As current e-payment systems do not offer the ability for shoppers to control their payment information in online transactions with the service providers (merchants). Therefore a method for providing control to shoppers would require some innovation to current e-payment mechanisms. Applying this to the MDPS, a new scheme that provides online shoppers some ability to control their personal payment information will most likely have a positive influence on their willingness to adopt a MDPS. Based on the aforementioned, the following can be hypothesized:

Hypothesis 1: A Shopper's perception that they have the ability to control their online transaction information that is provided to external parties by a MDPS will increase their willingness to adopt the MDPS.

\section{B. Perceived security}

According to Keyer [10], security is defined as a concrete technical solution such as using cryptography algorithms to satisfy the four fundamental security requirements: confidentiality, authentication, integrity, and non-repudiation. Security mechanisms may very well produce a system that works efficiently but it does not guarantee that the system will be trusted and used. Therefore we adopt the concept of perceived security, which is a subjective measure of security that refers to the degree to which people believe that using a particular payment system is secure [3].

The adoption factor for shoppers to use an e-payment system is the shopper's perceptions of the security solutions in that system. In other words, a shopper's perception of the security built into a MDPS will enhance their trust perceptions to online transactions, and hence increase their willingness to adopt a MDPS.

Hypothesis 2: The degree of a shopper's perceived security of a MDPS will influence their willingness to adopt the MDPS.

\section{C. perception of security evidence}

Perceived security evidence refers to the buyer's perception of security prior to making a transaction. It refers to the knowledge by the shopper that the purchase will be done through a trusted acquirer, and that the acquirer has the ability to fulfill security requirements, such as authentication, integrity, encryption, and non-repudiation. The shopper knows that it is the responsibility of the acquirer to verify that the merchant is accredited by a known trusted third party. The perceived security evidence can be influenced by implicitly perceptible measures that consumers encounter in the process of conducting e-payment transactions. While the shoppers trust in the security solutions is a subjective belief, the mechanisms that serve to form the perceived security evidence are built upon the prior knowledge of objective technological solutions.

Hypothesis 3: Prior perception of security evidence associated with a MDPS will increase shoppers' willingness to adopt a MDPS.

\section{Perception that no personal data is sent through the merchant}

A shopper's perception that no personal data is available to the merchant is related to the prior security evidence of the transaction. Consumers know that their personal information will not be sent through the merchant and will therefore not be available to be viewed, stored or manipulated during transit. This captures an objective measurement and denotes a real perception for assessing merchant risk rather than a personal anticipation. Consequently, the fact that a shopper perceives that no personal data is sent through the merchant can be as important in increasing a shopper's willingness to use a MDPS as is the role of prior perceived security in e-payment transactions.

Hypothesis 4: A shopper's perception that no personal data is sent to the merchant associated with a MDPS will increase that shopper's willingness to adopt a MDPS.

\section{E. Perceived ease of use and Perceived usefulness}

The Technology Acceptance Model (TAM) has been proposed to explain user adoption and acceptance of new technologies [5]. TAM purports the perceived ease of use and the perceived usefulness of a system as being the two major factors influencing attitudes toward the system's use. Perceived usefulness is defined here as the degree to which a shopper believes that a MDPS would facilitate the e-payment process. Instant authorization, fast payments and minimal intervention are just some of the benefits that could make a MDPS a viable proposition for e-payment systems.

Perceived ease of use is defined here as the degree to which a shopper believes that installing and managing a MDPS would be free of effort. Drawing from TAM, perceived usefulness and perceived ease of use of performing the behavior would directly influence behavioral intention and actual behavior. Applying this to the study, a MDPS that is perceived to 
facilitate the payment process and be of benefit, while also being easy to operate, is likely to be more accepted by shoppers.

Hypothesis 5: Perceived ease of use of a MDPS will increase shoppers' willingness to adopt a MDPS.

Hypothesis 6: Perceived usefulness of a MDPS will increase shoppers' willingness to adopt a MDPS.

\section{F. Perceived trust}

A shopper's trust in a merchant can play a significant role in determining the shopper's actions regarding that merchant. Empirical research has shown that trust increases a shopper's intention to purchase a product from a merchant [11]. We expect our results to reflect those past findings. For the purpose of this study, the term perceived trust (PT) is defined as the degree to which a shopper believes that using a particular electronic payment system (MDPS) would be secure.

Hypothesis 7: A shoppers' intention to adopt a MDPS is positively related to their trust in online shopping.

Hypothesis 8: A shoppers' trust in online payment will positively affect their intentions to purchase online.

\section{RESEARCH METHODOLOGY}

\section{A. Sample and procedure}

Using the insights gained from the literature and a discussion meeting phase, an online survey instrument has been developed. In total, 118 cases were gathered for about two months, but there were some missing values in the sample and there were some inappropriate cases. Thus, only 101 cases were finally analyzed.

\section{B. Data analyses}

Structural equation modeling (SEM) analysis using AMOS software was employed to examine the research model. The population of interest was individuals with experience in using e- payment systems.

Internal consistency reliability is a statement about the stability of individual measurement items across replications from the same source of information. Large Cronbach's alpha coefficients are usually signs that the measures are reliable [12, 13]. Construct validity indicates whether or not the measures chosen are true constructs describing the event. Cronbach's alpha was used for assessing the reliability of the items and Principal component analysis using varimax rotations was used for assessing the construct validity of the items. The alpha value was 0.87 . Hair, et al. [14] suggested that the lowest limit for Cronbach's alpha should be 0.70 so all constructs in the research model demonstrated acceptable reliability.

\section{The measurement model}

Testing the structural model would be meaningless until it has been established as a good measurement model. From our initial analysis, of the 8 independent constructs in the hypothesized model, a confirmatory factor analysis (CFA) for the balance was carried out to examine their psychometric properties. Measurement models for these constructs (latent variables) were quite acceptable; all values of RMR, GFI,
AGFI, NFI and TLI satisfied the recommended value [14] as shown in Table 1. In summary, the results demonstrated satisfactory convergent and discriminate validity of the measures.

TABLE I. MODEL COMPARISON (MODEL FIT INDICES OF COMPETING MODEL)

\begin{tabular}{|l|l|l|l|}
\hline & $\begin{array}{c}\text { Proposed } \\
\text { model }\end{array}$ & $\begin{array}{c}\text { Final competing } \\
\text { model }\end{array}$ & $\begin{array}{c}\text { Recommended } \\
\text { value }\end{array}$ \\
\hline Chi-square & 76.43 & 56.37 & $>0.05$ \\
\hline P-value & 0.001 & 0.83 & $<0.05$ \\
\hline X2/d.f square & 1.74 & 1.31 & $<0.06$ \\
\hline $\begin{array}{l}\text { Root mean of } \\
\text { residual (RMR) }\end{array}$ & 0.58 & 0.055 & $>0.90$ \\
\hline $\begin{array}{l}\text { Root mean square of } \\
\text { error of estimation } \\
\text { (RMSEA) }\end{array}$ & 0.086 & 0.056 & $>0.80$ \\
\hline Goodness-of-fit (GFI) & 0.89 & 0.92 & $>0.90$ \\
\hline $\begin{array}{l}\text { Adjusted Goodness-of- } \\
\text { fit index (AGFI) }\end{array}$ & 0.81 & 0.85 & $>0.90$ \\
\hline Normed fit index (NFI) & 0.92 & 0.94 & $>0.90$ \\
\hline $\begin{array}{l}\text { Tucker-Lewis index } \\
\text { (TLI) }\end{array}$ & 0.95 & 0.98 & 0.99 \\
\hline $\begin{array}{l}\text { Comparative fit index } \\
\text { (CFI) }\end{array}$ & 0.95 & 05 & \\
\hline
\end{tabular}

\section{Test of the structural model}

The proposed model was next tested. The GFI indices for the hypothesized model reflected an acceptable model (x2/d.f. $=1.31, \mathrm{P}=0.83, \mathrm{TLI}=0.98, \mathrm{CFI}=0.99, \mathrm{RMSEA}=0.06)$. To investigate the validity of the hypothesized model, an alternative model was considered and analyzed and then compared with the proposed model. The AMOS software test indicates how to modify the proposed model so that it results in our final computing model in Fig. 2. Table 1 displays the measures of fit for the proposed model and the final competing model, suggesting that the final competing model was significantly better in acceptable fits of RMSEA and CFI. The RMR, GFI, AGFI, NFI and TLI were also in the acceptable level, indicating further support for the final competing model over the proposed model. The results supporting the final competing model and indicate that: the shopper's ability to control their transaction (PC); the security built into a mobile phone (MSEC); the prior perception of security evidence (PSE); the perception that no personal data is sent through the merchant in a transaction (NDTM); the perceived ease of use (PEOU); and the perceived usefulness (PU); were all significant factors in affecting people to adopt the MDPS as a new payment system. The results also indicated that the shopper's adoption of the MDPS will increase their intention to purchase online in the future.

The data showed that the security built into a mobile phone MSEC has the strongest direct effect on the adoption of a MDPS $(\beta=0.97, \mathrm{P}<0.001)$. Further, PT had a very strong positive effect on their intention to purchase online $(\beta=0.90, \mathrm{P}$ $<0.001)$. The contribution of perceived usefulness (PU) on PT $(\beta=0.20, P=0.017)$ was substantially lower. It should also be noted that perceived usefulness (PU) had an effect on the adoption of a MDPS. 


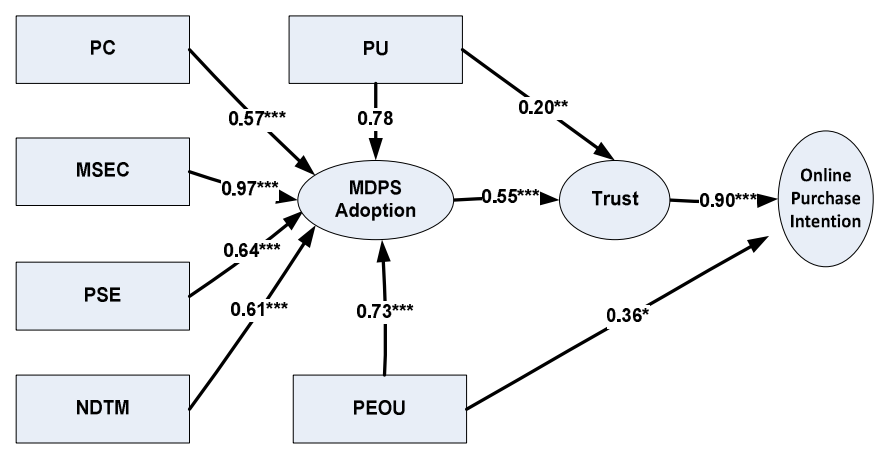

Significance at $\mathrm{p} * * *:<0.001,{ }^{* *}: 0.02, *: 0.008$

Figure 2. The final competing model.

The final competing model demonstrated that the shopper's prior perception of security evidence (PSE), their perception that no personal data is sent through the merchant (NDTM) and their perception of their ability to control their transaction (PC) had an effect on their willingness to adopt a MDPS $(\beta=0.64$, 0.61 and $0.57, \mathrm{P}<0.001)$ respectively. The data also showed that perceived ease of use (EOU) had a strong effect on their willingness to adopt a MDPS and a small direct effect on their intention to purchase online. Thus the all the proposed research hypothesizes were accepted.

\section{DISCUSSION}

The study examined the influence of using mobile devices to enhance an online shopper's trust in the use of e- payment systems. It also investigated whether the availability of a security-enabled mobile phone, modified to provide added security for an online shopper's payment details, would influence their decision to use online shopping.

Results indicated that there was a positive relationship between the use of a mobile device for online transactions and a shopper's trust in the transaction. The analysis provided strong support for the proposed research model. In particular, the results demonstrated that the four variables (PC, NDTM, PT, and MSEC) have a significant direct effect on the adoption of mobile devices as added security to gain shoppers' trust in epayment systems and thus increase their utilization of online shopping. Our findings are consistent with those of researchers such as David et al., [15, 16]. Thus, perceived usefulness should be an important concern for managers and executives when implementing IT systems.

The results demonstrate that the adoption of mobile devices have significant and direct effects on shoppers' trust. Mobile devices adoption depends on how the adoption is perceived and used by shoppers. From the perspective of theory development, this study has posited and found empirical support that the use of a mobile device drives shoppers to use e-payment systems through a positive influence on their perceptions of trust in epayment systems.

\section{CONCLUSION AND FUTURE WORK}

This paper has examined the factors that may influence online shoppers' trust in their use of e- payment systems and the effects of the adoption of a MDPS on their intention to purchase online. The study suggests that there are four variables (PC, NDTM, PT, and MSEC) that have significant direct effect on the adoption of mobile devices to be used as trust devices in online transactions, and that will help gain shoppers' trust in e-payment systems and increase their intention to use online shopping in the future.

Clearly, additional research is needed to show that the research model can be practically applied to online shopping, this study takes a first step in that direction by proposing such a model and demonstrating its reliability and validity.

\section{REFERENCES}

[1] Mayer, R.C., \& Davis, J. H, An integrative model of organizational trust. . Academy of Management Review, 1995. 20(3): p. 709-734.

[2] Andert Donna, Wakefield Robin, and W. Joel, Professional services security practice. Sun BluePrints OnLined, December 2002.

[3] Pousttch, K., D. G, and Wiedemann, What Influences Consumers' Intention to Use Mobile Payments? 2007, University of Augsburg, Germany.

[4] Thair, A.-D.i., S. Luo, and Peter Summons. Using a mobile device to enhance customer trust in the security of remote transactions. in Computer and Information Technology, 2008. CIT 2008. 8th IEEE International Conference on. 2008.

[5] Davis F.D., B.R.P. and Warshaw P. R., 'User Acceptance of Computer Technology: A Comparison of Two Theoretical Models', Management Science, no. 35, pp. 982-1003. 1989.

[6] Venkatesh V. and Davis F.D., 'A theoretical extension of the technology acceptance model: Four longitudinal field', Management science, no. 46, pp. 186-204. 2000.

[7] Marios, K., K. Ajit, and L. Priscilla Ann, Consumer Behavior in WebBased Commerce: An Empirical Study. Int. J. Electron. Commerce, 2001-2002. 6(2): p. 115-138.

[8] Jawaid, A.G., S. Roberta, and R. Pamela, The experience of flow in computer-mediated and in face-to-face groups, in Proceedings of the twelfth international conference on Information systems. 1991, University of Minnesota: New York, New York, United States.

[9] Smith, A. and R. Bolton, The effect of customers' emotional responses to service failures on their recovery effort evaluations and satisfaction judgments. Journal of the Academy of Marketing Science, 2002. 30(1): p. 5-23.

[10] 1Kreyer, N., K. Pousttchi, and K. Turowski, Standardized Payment Procedures as Key Enabling Factor for Mobile Commerce. 2002, University Library of Munich, Germany.

[11] 1Sirrka, L.J. and A.T. Peter, Consumer reactions to electronic shopping on the world wide web. Int. J. Electron. Commerce, 1996. 1(2): p. 59-88.

[12] Blunch, N.J., Introduction to structural equation modelling using SPSS and AMOS. 2008, London: SAGE.

[13] Ho, R., Handbook of univariate and multivariate data analysis and interpretation with SPSS 2006, Boca Raton, Fla.: Chapman \& Hall/CRC.

[14] Joseph F. Hair, R.E.A., William C. Black, Ronald L. Tatham, Multivariate Data Analysis. 1998: Prentice Hall.

[15] Keil, M., P.M. Beranek, and B.R. Konsynski, Usefulness and ease of use: field study evidence regarding task considerations. Decision Support Systems, 1995. 13(1): p. 75-91.

[16] Adams, D., R. Nelson, and P. Todd, Perceived usefulness, ease of use, and usage of information technology: a replication. MIS Q., 1992. 16(2): p. 227-247. 